\title{
Investigation of the optimum conditions for adsorptive hydrogen storage
}

\author{
Stephan Glante ${ }^{1} \cdot$ Marcus Fischer $^{1} \cdot$ Martin Hartmann ${ }^{1}[$
}

Received: 19 May 2021 / Accepted: 18 June 2021 / Published online: 9 July 2021

(c) The Author(s) 2021

\begin{abstract}
Cryogenic adsorption using microporous materials is one of the emerging technologies for hydrogen storage in fuel cell vehicles. Metal-organic frameworks have been identified as suitable adsorbents exhibiting large hydrogen sorption at $77 \mathrm{~K}$. With respect to technical realization, in this work, the deliverable capacity at the optimal storage temperature was determined for a series of MOFs in comparison to zeolite $\mathrm{Ca}-\mathrm{A}$. The deliverable capacity is defined as the amount of hydrogen released between a maximum tank pressure and a minimum back pressure and shows a maximum which defines the optimum operating temperature. This optimum operating temperature depends on the pore size of the adsorbent and the chemical properties of the surface. A number of materials are identified that exhibit optimal operating temperatures well above $100 \mathrm{~K}$. A higher optimal storage temperature, however, typically results in a lower deliverable capacity.
\end{abstract}

Keywords Hydrogen storage $\cdot$ MOFs $\cdot$ Zeolites $\cdot$ Deliverable capacity $\cdot$ Temperature dependence of hydrogen adsorption

\section{Introduction}

Hydrogen is regarded as a promising alternative energy vector for fossil fuels. Therefore, many technologies to store hydrogen are currently investigated [1]. These technologies vary from pressurized vessels over liquid storage to chemical storage in hydrides [2-4] or liquid organic hydrogen carriers (LOHC) [5-7]. Another large field of interest is the adsorptive storage of hydrogen in porous materials such as activated carbons [8-10], zeolites [11, 12], porous polymers [13], and metal-organic frameworks (MOFs) [14, 15]. For these materials, it was shown experimentally that the maximum of adsorbed hydrogen depends on the surface area of the porous material [8]. "Chahines rule" predicts that at a temperature of $77 \mathrm{~K}$, the maximum $\mathrm{H}_{2}$ storage capacity increases linearly by $2 \mathrm{wt}-\%$, when the surface area rises by $1000 \mathrm{~m}^{2} \mathrm{~g}^{-1}$. At room temperature, the increase in capacity is predicted to be $0.23 \mathrm{wt}-\%$ for the same increase of surface area. It was shown theoretically by Züttel et al. [9] that the maximum surface concentration of hydrogen on a graphene

Martin Hartmann

martin.hartmann@fau.de

1 Erlangen Center for Interface Research and Catalysis,

Friedrich-Alexander-Universität Erlangen-Nürnberg,

Egerlandstraße 3, 91058 Erlangen, Germany layer is $2.28 \mathrm{wt}-\%$ per $1000 \mathrm{~m}^{2} \mathrm{~g}^{-1}$ when the surface has no curvature and the hydrogen is hexagonally closed packed. "Chahines rule" was tested and found that it is not only applicable for activated carbons [10] but also for zeolites $[11,16]$, MOFs [17, 18], and Prussian blue analogues [14]. While it is always good to know the maximum amount of hydrogen that can be adsorbed on a given porous material, it is worth noting that for technical realization, the deliverable capacity between two pressures is more suitable to compare porous materials. It is energetically not economic to empty hydrogen tanks below atmospheric pressure since a vacuum needs to be applied to release the remaining amount of hydrogen. Compressors also need additional energy; therefore, it is not useful to store hydrogen at higher pressures than delivered by the means of hydrogen production. Commercial electrolyzers deliver hydrogen with a pressure of 30 bar [19], while hydrogen with a pressure between 10 and 40 bar of is received from steam reformers [20].

The deliverable capacity between two pressure points was first investigated by Bhatia and Myers [21]. They employed the Langmuir isotherm (1) to describe the adsorption of hydrogen on the activated carbon AX-21.

$n=n_{m} \cdot \frac{K \cdot p}{1+K \cdot p}$ 
The adsorbed amount $n$ depends on the adsorption capacity $n_{m}$, the equilibrium constant $K$, and the pressure $p$. The deliverable capacity $\mathrm{D}$ can be described as the difference between two pressures $p_{1}$ and $p_{2}$ (2). Bhatia and Myers used $p_{1}=30$ bar and $p_{2}=1.5$ bar for their calculations.

$D\left(K, p_{1}, p_{2}\right)=\frac{n_{m} \cdot K \cdot p_{1}}{1+K \cdot p_{1}}-\frac{n_{m} \cdot K \cdot p_{2}}{1+K \cdot p_{2}}$

The maximal deliverable capacity for two fixed pressures is reached for (3)

$K=\frac{1}{\sqrt{p_{1} \cdot p_{2}}}$

Using the relationship between the Gibbs-Helmholtz equation and the equation for the chemical equilibrium, the adsorption constant can be described even further with Eq. (4), $\mathrm{p}_{0}$ denotes the standard pressure ( $\left.1 \mathrm{bar}\right), \Delta \mathrm{H}^{\circ}$ is the standard enthalpy change on adsorption, and $\Delta S^{\circ}$ is the standard entropy change

$-R T \cdot \ln \frac{K}{p_{0}}=\Delta G^{\circ}=\Delta H^{\circ}-T \cdot \Delta S^{\circ}$

Using Eqs. (3) and (4), the optimal heat of adsorption can be calculated for a specific pressure set and a given temperature employing Eq. (5).

$\Delta H^{\circ}{ }_{o p t}=T \cdot \Delta S^{\circ}+\frac{R T}{2} \ln \left(\frac{p_{1} \cdot p_{2}}{p_{0}^{2}}\right)$

For $\mathrm{p}_{1}=30$ bar, $\mathrm{p}_{2}=1.5 \mathrm{bar}$, a temperature of $\mathrm{T}=298 \mathrm{~K}$, and the assumption that $\Delta S^{\circ} \approx-8 \mathrm{R}$, Bhatia and Myers calculated an optimal adsorption enthalpy for $\mathrm{H}_{2}$ of $\Delta \mathrm{H}^{\circ}{ }_{\text {opt }}=-15.1 \mathrm{~kJ} \mathrm{~mol}^{-1}[21]$.

While the original paper is cited many times, to the best of our knowledge, only three other groups reported investigations on the temperature-dependent deliverable capacity. Tedds et al. calculated the deliverable capacity in the pressure range between 2 and 15 bar for different MOFs, zeolites, and carbons [22]. They showed that the highest sorption capacity is not always found at $77 \mathrm{~K}$ and that the temperature dependency is different depending on the material investigated. Purewal et al. mixed MOF5 with expanded natural graphite to improve the thermal conductivity. There, a pressure range between 5 and 100 bar was employed [23]. It was shown that the maximum hydrogen capacity of MOF-5 is reached approximately at $103 \mathrm{~K}$ and does not change, when the thermal conductivity is altered by the addition of expanded natural graphite. Schlichtenmayer and Hirscher investigated the temperature-dependent sorption swing of several members of the DUT family in comparison with activated carbons and several other MOFs [24] and showed that the optimum operating temperature is influenced by the enthalpy of adsorption.

In this contribution, we present hydrogen sorption isotherms of several porous materials and calculated their different deliverable $\mathrm{H}_{2}$ capacity behavior. The deliverable capacity is temperature dependent with a material-specific maximum in the range between 80 and $135 \mathrm{~K}$. We show that it is feasible to calculate the deliverable capacity from measurement at three different temperatures $(77,195$, and $273 \mathrm{~K}$ ) in good agreement to experiments where many temperatures were used.

\section{Experimental section}

Zeolite Ca-A (Köstrolith 5AK) was generously provided by Chemiewerk Bad Köstritz (CWK). ZIF-8 was synthesized as described in our previous publication [25]. In a typical synthesis, 8.04 (27 mmol) of zinc nitrate hexahydrate and $4.43 \mathrm{~g}$ (54 mmol) of 2-methylimidazol were dissolved in $200 \mathrm{ml}$ of DMF. The mixture was heated to $130{ }^{\circ} \mathrm{C}$ and stirred for $24 \mathrm{~h}$. The resulting suspension was filtered, soxhlet extracted for $48 \mathrm{~h}$ with methanol, and finally dried at $60{ }^{\circ} \mathrm{C}$ in a vacuum oven for $12 \mathrm{~h}$.

UiO-67 was synthesized according to the literature recipe [26]. In a $250-\mathrm{ml}$ Schott bottle, $0.734 \mathrm{~g}(3.15 \mathrm{mmol})$ of zirconium tetrachloride and $0.763 \mathrm{~g}(3.15 \mathrm{mmol})$ of 4,4'-biphenyldicarboxylic acid were mixed in $125 \mathrm{ml}$ of DMF and $0.7 \mathrm{ml}$ of water. After stirring for $1 \mathrm{~h}$, the bottle was placed in a preheated oven at $120^{\circ} \mathrm{C}$ for $24 \mathrm{~h}$. After cooling, the precipitate was filtered and cleaned via soxhlet extraction in ethanol for a day.

HKUST-1 was synthesized by dissolving $4.23 \mathrm{~g}$ $(0.02 \mathrm{~mol})$ of trimesic acid in $94 \mathrm{ml}$ of ethanol and suspending $1.95 \mathrm{~g}(0.02 \mathrm{~mol})$ of copper hydroxide in $36 \mathrm{ml}$ of water [27]. After combining the two solutions, the mixture was stirred for $19 \mathrm{~h}$ at room temperature, filtered, and then extracted with ethanol in a soxhlet apparatus for $24 \mathrm{~h}$. Finally, the powder was dried at $120^{\circ} \mathrm{C}$ for 2 days.

MIL-100(Fe) was prepared according to ref. [28]. $6.26 \mathrm{~g}$ $(15.5 \mathrm{mmol})$ of iron(III) nitrate nonahydrate were dissolved in $90 \mathrm{ml}$ of water and filled into a $125 \mathrm{ml}$ autoclave. $3.6 \mathrm{ml}$ of concentrated nitric acid was added, which turned the orangebrown solution clear. After adding $2.22 \mathrm{~g}(10.6 \mathrm{mmol})$ of trimesic acid, the mixture was stirred for $2 \mathrm{~h}$. The autoclave was closed and placed in an oven at $30^{\circ} \mathrm{C}$. The temperature was increased with a rate of $2 \mathrm{~K} \mathrm{~min}^{-1}$ until the final temperature of $160{ }^{\circ} \mathrm{C}$ was reached. The temperature was held for $48 \mathrm{~h}$. The autoclave was then cooled to room temperature at ambient conditions. The brown suspension was washed 
several times with water and the remaining impurities were removed via soxhlet extraction in ethanol for 2 days.

Hydrogen adsorption isotherms were measured with a Rubotherm Isosorp HyGra instrument. Temperatures of $77 \mathrm{~K}$ and $195 \mathrm{~K}$ were accomplished with Dewars filled with liquid nitrogen and a mixture of dry ice and isopropanol, respectively. Isotherms at room temperature were measured employing a JULABO thermostat. The powder samples (appr. $200 \mathrm{mg}$ ) were activated at $170{ }^{\circ} \mathrm{C}$ in a vacuum using electrical heating. The $\mathrm{H}_{2}$ isotherms were measured up to a pressure of 50 bar with an equilibration time of $40 \mathrm{~min}$ for each step. In order to prevent errors due to helium adsorption, buoyancy correction was measured at $0{ }^{\circ} \mathrm{C}$. The cycle experiments with ZIF-8 and HKUST-1 were conducted with the same instrument at $77 \mathrm{~K}$. Here, the segments were chosen to alternate between 1 and 30 bar with an equilibration time of 30 and $60 \mathrm{~min}$, respectively. Since the MSB uses gravimetric measurements, the pressure can be set easily and the corresponding mass is recorded.

Hydrogen adsorption isotherms at different temperatures between -203 and $-78{ }^{\circ} \mathrm{C}$ were recorded with a home-built closed-cycle sorption unit with an ARS Closed Cycle Cryostat and a Lakeshore high precision temperature controller. Using this setting, isotherms between $20 \mathrm{~K}$ and room temperature up to a pressure of $30 \mathrm{bar}$ were recorded. Prior to the measurement, the sample was degassed in a vacuum at $170{ }^{\circ} \mathrm{C}$ for $12 \mathrm{~h}$.

Nitrogen sorption isotherms were recorded with a Micromeritics ASAP 2010 instrument. BET areas were calculated according to the recommendations from IUPAC and Rouquerol et al. [29, 30].

\section{Results and discussion}

The X-ray diffraction patterns of ZIF-8, HKUST-1, UiO67 , and MIL-100(Fe) are in good agreement with the simulated patterns (Fig. 1) confirming the synthesis of MOFs with high purity.

Nitrogen sorption was used to determine the BET surface area and the pore volume at $0.8 \mathrm{p} / \mathrm{p}_{0}$ for all synthesized MOFs (see Table 1).

The hydrogen sorption isotherms at $77 \mathrm{~K}$ of five different molecular sieves are compared in Fig. 2. All isotherms are of type I according to the IUPAC classification. HKUST- 1 shows with $45 \mathrm{mg} \mathrm{g}^{-1}$ the highest sorption capacity, while zeolite $\mathrm{Ca}-\mathrm{A}$ exhibits the lowest capacity with $16 \mathrm{mg} \mathrm{g}^{-1}$. The isotherms of UiO-67, ZIF-8, and MIL-100(Fe) fall in between those of HKUST-1 and zeolite Ca-A, with saturation capacities of $39.5 \mathrm{mg} \mathrm{g}^{-1}$, $33.3 \mathrm{mg} \mathrm{g}^{-1}$, and $33.6 \mathrm{mg} \mathrm{g}^{-1}$, respectively. Interestingly,

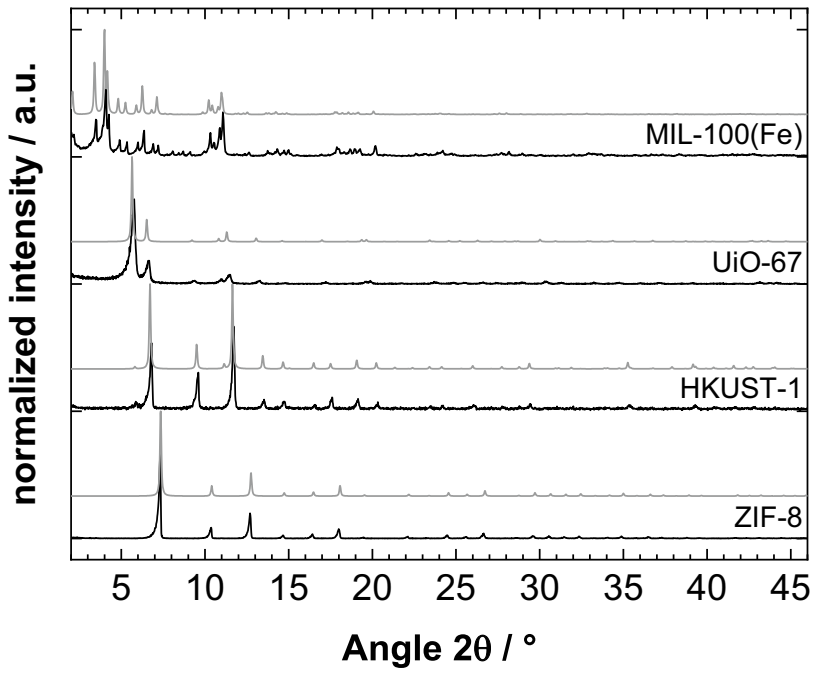

Fig. 1 Powder X-ray diffraction patterns of ZIF-8, HKUST-1, UiO67 , and MIL-100(Fe) (black) in comparison to their simulated diffraction patterns (grey)

below pressure of 10 bar, the isotherm of ZIF- 8 lies above the isotherm of UiO- 67 .

As mentioned before, releasing hydrogen from pressure vessels below ambient pressure is not energy efficient. Storing hydrogen at pressures exceeding 30 bar than delivered by the means of production like electrolysis or steam reforming is not economical, as well. Thus, the deliverable capacity was calculated between 0.9 and 30 bar. The pressure of 0.9 bar was chosen due to instrumental restrictions. The deliverable capacity at $77 \mathrm{~K}$ for ZIF-8 $\left(21.31 \mathrm{mg} \mathrm{g}^{-1}\right)$ is larger than the deliverable capacity of HKUST-1 (19.94 $\mathrm{mg} \mathrm{g}^{-1}$ ) (Figs. 3 and 4). The deliverable capacity of UiO-67 amounts to $28.06 \mathrm{mg} \mathrm{g}^{-1}$ and $21.22 \mathrm{mg} \mathrm{g}^{-1}$ for MIL-100(Fe). At $195 \mathrm{~K}$, the deliverable capacity for all MOFs is smaller than that at $77 \mathrm{~K}$, with the capacity of HKUST-1 having now a larger value $\left(6.72 \mathrm{mg} \mathrm{g}^{-1}\right)$ than that of ZIF-8 (2.91 $\mathrm{mg} \mathrm{g}^{-1}$ ) (see Table 2).

While the deliverable capacity of zeolite Ca-A decreases only slightly with an increasing temperature, a strong decrease is found for the MOFs under study. At $77 \mathrm{~K}$, it is calculated to be $4.15 \mathrm{mg} \mathrm{g}^{-1}$, whereas at $195 \mathrm{~K}$ it is $3.94 \mathrm{mg} \mathrm{g}^{-1}$.

Table 1 BET surface areas and pore volumes of all investigated MOFs

\begin{tabular}{lll}
\hline Material & BET surface area $/\left(\mathrm{m}^{2} \mathrm{~g}^{-1}\right)$ & Pore volume $/\left(\mathrm{cm}^{3} \mathrm{~g}^{-1}\right)$ \\
\hline Zeolite Ca-A & 702 & 0.27 \\
HKUST-1 & 1777 & 0.73 \\
UiO-67 & 2169 & 1.00 \\
ZIF-8 & 1827 & 0.67 \\
MIL-100(Fe) & 2033 & 0.91 \\
\hline
\end{tabular}




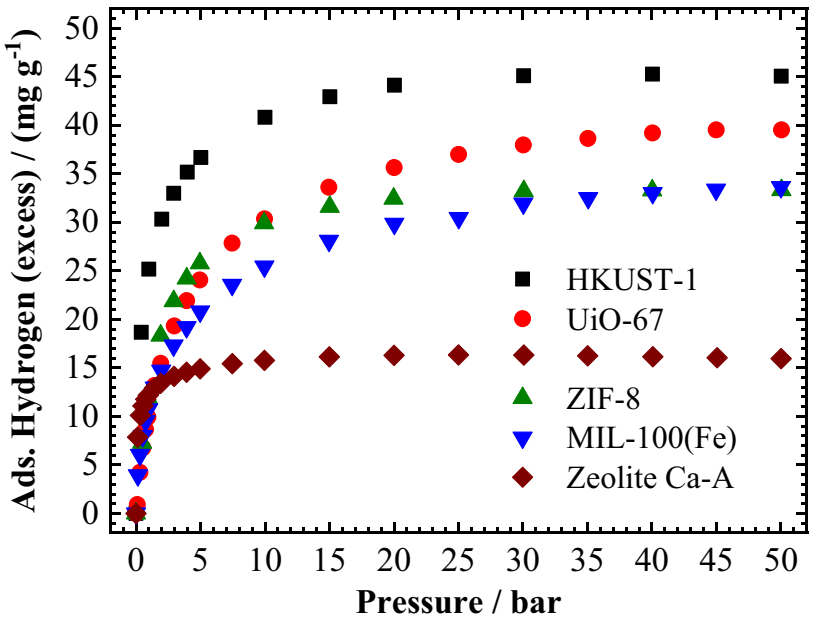

Fig. 2 Hydrogen sorption isotherms at $77 \mathrm{~K}$ of HKUST-1, UiO-67, ZIF-8, MIL-100(Fe), and zeolite Ca-A

For each adsorbent, the isotherms at three different temperatures were fitted using the Tóth isotherm with temperature-dependent parameters [31]. The parameters for all materials are collected in Table 2.

The Tóth isotherm is described with the following equation:

$q(p)=q_{\max } \cdot \frac{b \cdot p}{\left[1+(b \cdot p)^{t}\right]^{\frac{1}{t}}}$

where $q$ is the capacity, $q_{\max }$ is the maximum capacity, $b$ is the affinity, and $t$ is the heterogeneity factor. According to reference [31] $q_{\max }, b$ and $t$ can be described with the following equations to take into account the temperature dependence of these parameters. $T_{0}$ is a reference temperature and was chosen to be $77 \mathrm{~K}$.

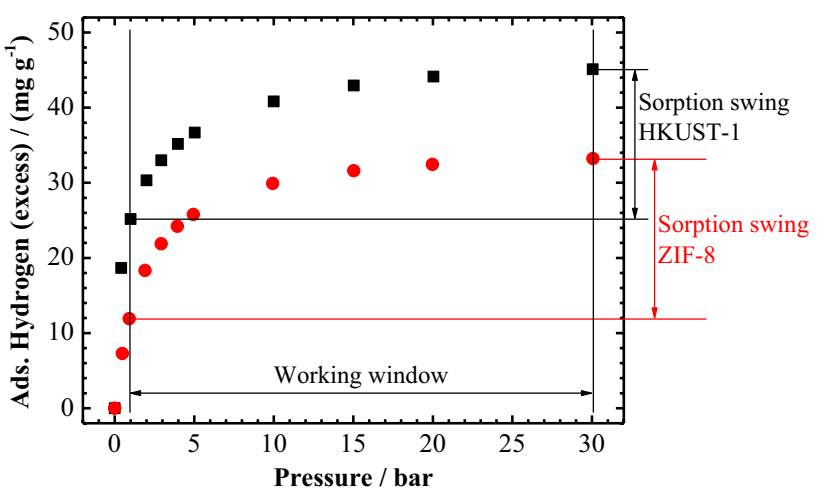

Fig. 3 Visualization of the deliverable capacity of HKUST-1 and ZIF-8 in the working window from 1 to $30 \mathrm{bar}$

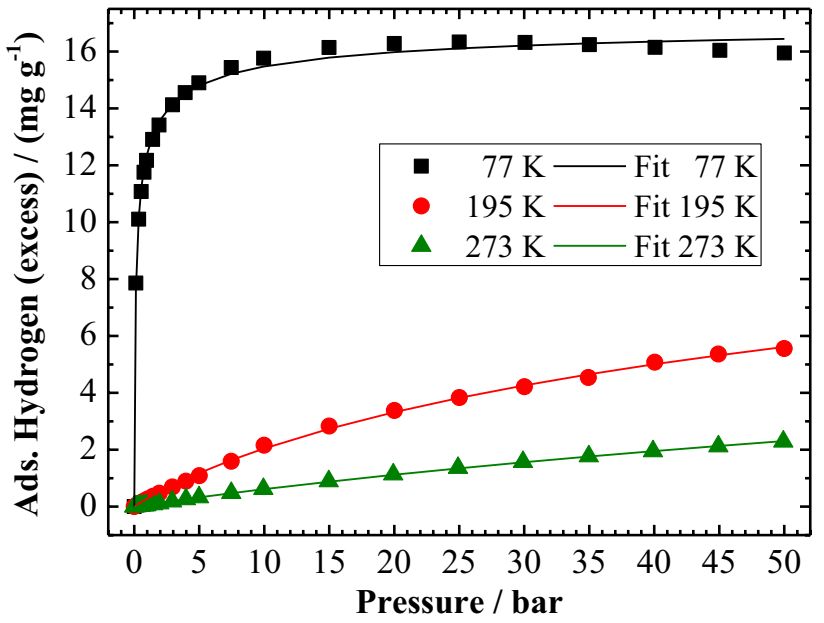

Fig. 4 Hydrogen sorption isotherm of zeolite $\mathrm{Ca}-\mathrm{A}$ at three different temperatures and fit (solid line) with Tóth isotherm for all three temperatures

$t=t_{0}+\alpha \cdot\left(1-\frac{T_{0}}{T}\right)$

$b=b_{\infty} \cdot \exp \left(\frac{Q}{R \cdot T}\right)$

$q_{\max }=q_{\max , 0} \cdot \exp \left[\chi \cdot\left(1-\frac{T}{T_{0}}\right)\right]$

It is worth mentioning that $Q$ is not to be mistaken with the isosteric heat of adsorption $Q_{s t}$ or enthalpy of adsorption $\Delta_{\mathrm{ads}} \mathrm{H}$ [31]. It is just a fit parameter, which has the same units in the same order of magnitude as heats of adsorption. A comprehensive guide to calculating the heat of adsorption can be found in ref. [32]. Here it is shown that the heat of adsorption also depends on the loading and that one should perform the calculation using isotherms collected in a small temperature range. We used the fitting parameters over a wide range of temperatures, making the

Table 2 Deliverable capacity of all investigated materials between 0.9 and 30 bar at $77 \mathrm{~K}$ and $195 \mathrm{~K}$

\begin{tabular}{lll}
\hline & $\begin{array}{l}\text { Deliverable capacity at } \\
77 \mathrm{~K} /\left(\mathrm{mg} \mathrm{g}^{-1}\right)\end{array}$ & $\begin{array}{l}\text { Deliverable capacity } \\
\text { at } 195 \mathrm{~K} /\left(\mathrm{mg} \mathrm{g}^{-1}\right)\end{array}$ \\
\hline HKUST-1 & 19.94 & 6.72 \\
UiO-67 & 28.06 & 4.55 \\
ZIF-8 & 21.31 & 2.91 \\
MIL-100(Fe) & 21.22 & 4.93 \\
Zeolite Ca-A & 4.15 & 3.94 \\
\hline
\end{tabular}


Table 3 Fit parameters according to hydrogen adsorption isotherms at temperatures of 77,195 , and $273 \mathrm{~K}$

\begin{tabular}{lccccc}
\hline & HKUST-1 & UiO-67 & ZIF-8 & MIL-100(Fe) & Zeolite Ca-A \\
\hline $\mathrm{q}_{\max } /\left(\mathrm{mg} \mathrm{g}^{-1}\right)$ & 50.87 & 45.72 & 35.00 & 46.11 & 17.32 \\
$\chi /-$ & 0.00 & 0.33 & 0.04 & 0.35 & 0.09 \\
$\mathrm{Q} /\left(\mathrm{kJ} \mathrm{mol}^{-1}\right)$ & 6.62 & 4.35 & 5.45 & 4.73 & 7.83 \\
$\mathrm{~b}_{\infty} / 10^{-4} \mathrm{bar}^{-1}$ & 1.33 & 4.19 & 1.15 & 6.91 & 1.65 \\
$\mathrm{t}_{0} /-$ & 0.54 & 0.76 & 1.00 & 0.47 & 0.49 \\
$\alpha /-$ & 0.11 & 0.58 & 0.00 & 0.28 & 0.33 \\
\hline
\end{tabular}

calculation of heat of adsorption or adsorption enthalpy scientifically unsound (Tables 3 and 4).

With these sets of parameters, the deliverable capacity between two pressures can be calculated for a specific temperature for each material.

$\Delta q(T)=q_{\max }(T) \cdot\left(\frac{b(T) \cdot p_{1}}{\left[1+\left(b(T) \cdot p_{1}\right)^{t(T)}\right]^{\frac{1}{t(T)}}}-\frac{b(T) \cdot p_{2}}{\left[1+\left(b(T) \cdot p_{2}\right)^{t(T)}\right]^{\frac{1}{t(T)}}}\right)$

The results of this calculation are shown in Fig. 5 for $\mathrm{p}_{1}=30 \mathrm{bar}$ and $\mathrm{p}_{2}=1 \mathrm{bar}$. The temperature dependence of the deliverable capacity shows a different maximum for each material. In our case, all maxima are at temperatures above $77 \mathrm{~K}$. The highest value of $27.80 \mathrm{mg} \mathrm{g}^{-1}$ is measured for UiO67 at a temperature of $82 \mathrm{~K}$. At $77 \mathrm{~K}$ MIL100, ZIF-8, and HKUST-1 show nearly the same values $\left(\sim 20 \mathrm{mg} \mathrm{g}^{-1}\right)$. The maximum values rise from $20.6 \mathrm{mg} \mathrm{g}^{-1}$ for MIL-100(Fe) over $24 \mathrm{mg} \mathrm{g}^{-1}$ (ZIF-8) to $26 \mathrm{mg} \mathrm{g}^{-1}$ for HKUST-1 at $79.5 \mathrm{~K}, 88.5 \mathrm{~K}$, and $97 \mathrm{~K}$, respectively. Zeolite Ca-A exhibits the lowest value $\left(8.8 \mathrm{mg} \mathrm{g}^{-1}\right)$ for the maximum deliverable capacity, however, at the highest temperature $(120 \mathrm{~K})$. For all other materials, the temperature of maximum capacity is observed at lower temperatures. In fact, the temperature of the capacity maximum seems to be dependent on the cage size. Smaller pore diameter leads to a higher temperature at maximum deliverable capacity. Bhatia and Myers reported that the deliverable capacity is temperature dependent and that the maximum deliverable capacity and its corresponding temperature depend on the pore size for a series of activated carbons with slit pores and carbon nanotubes with different diameters.

HKUST-1 exhibits peculiar behavior. The materials have the second-largest pore diameter, which should mean that it should exhibit the second lowest temperature for the maximum capacity. In contrast to this, it exhibits the second-highest temperature and an exceptionally slow slope towards higher temperatures. This may be assigned to the coordinatively unsaturated site of the copper ions in the framework. Peterson et al. showed that hydrogen adsorbs first at these unsaturated sites [33]. The saturation of those sites is reached at a $\mathrm{H}_{2}$ : $\mathrm{Cu}$ ratio of 1 , which corresponds to an adsorbed (excess) amount of $9.9 \mathrm{mg} \mathrm{g}^{-1}$. At a temperature of $77 \mathrm{~K}$, this is achieved with hydrogen pressures below $1 \mathrm{bar}$; for $195 \mathrm{~K}$, a pressure higher than 50 bar is needed (see Fig. S12). This means the deliverable capacity depends on the most active sites mostly at higher temperatures, leading to the high values observed above $100 \mathrm{~K}$. Thus, the hydrogen sorption capacity depends on both, the pore diameter and the chemical nature of the adsorbent [15, 34]. MIL100(Fe) has coordinatively unsaturated sites, as well, but here the large pore size contradicts the beneficial influence of the chemical nature. The influence of those coordinatively unsaturated sites shows up

Table 4 Maximum deliverable capacity between 1 and 30 bar and its corresponding temperature for all investigated materials

\begin{tabular}{|c|c|c|c|c|}
\hline Material & $\begin{array}{l}\text { Maximum deliverable } \\
\text { capacity } /\left(\mathrm{mg} \mathrm{g}^{-1}\right)\end{array}$ & $\begin{array}{l}\text { Temperature of maximum } \\
\text { deliverable capacity/K }\end{array}$ & Cages (diameter/Å) & Pore opening/Å \\
\hline HKUST-1 & 25.81 & 97.0 & $\begin{array}{l}1 \text { octahedron (4) } \\
2 \text { cuboctahedra (11) }\end{array}$ & 8 \\
\hline UiO-67 & 27.80 & 81.8 & $\begin{array}{l}2 \text { tetrahedra }(11) \\
1 \text { octahedron }(13)\end{array}$ & 9 \\
\hline ZIF-8 & 24.05 & 88.6 & 1 trunc. octahedron (13) & 4 \\
\hline MIL-100(Fe) & 20.57 & 79.5 & $\begin{array}{l}4 \text { tetrahedra (6) (inaccessible) } \\
2 \text { icosidodecahedra (23) } \\
1 \text { tetrahedron-derived cavity (28) }\end{array}$ & 8 \\
\hline Zeolite Ca-A & 8.76 & 120.3 & $\begin{array}{l}1 \text { trunc. cuboctahedron (10) } \\
1 \text { trunc. octahedron (6) }\end{array}$ & 5 \\
\hline
\end{tabular}




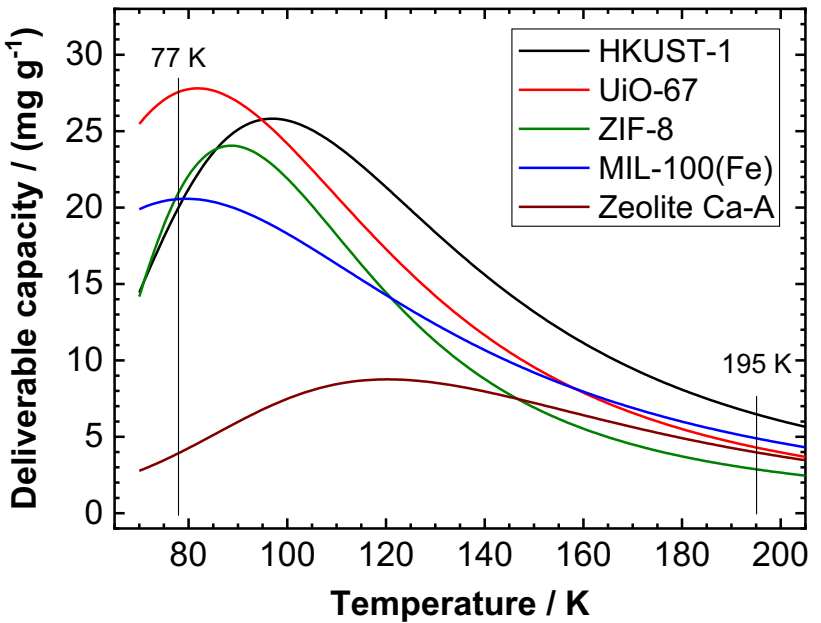

Fig. 5 Calculated temperature-dependent deliverable capacity for all investigated materials between 70 and $200 \mathrm{~K}$

at higher temperatures, where MIL-100(Fe) exhibits the second-largest capacity of all investigated materials.

The temperature dependence of the deliverable capacity is important for cycle experiments between 1 and 30 bar, as shown for ZIF-8 and HKUST-1 in Fig. 6. These experiments were carried out with the magnetic suspension balance, where the pressure values of 1 and 30 bar can be employed easily. Each segment had a duration of $60 \mathrm{~min}$. Due to the constant loss of liquid nitrogen from the cooling dewar, the temperature increases slightly over time. This temperature increase has two reasons: firstly, the dewar is tightly placed under the adsorption vessel and cannot be moved or refilled during the experiment. Therefore, the normal evaporation rate of nitrogen leads to a slow temperature increase. Secondly, contrary to standard sorption experiments, where the pressure is increased in slow steps, the pressure is changed rather rapidly in cycle experiments. This means, in each 30-bar segment warm hydrogen is pumped into the adsorption chamber and in the 1-bar segment cold hydrogen is released. Thus, the evaporation rate of nitrogen is increased by an additional amount. The whole cycle experiment is $48 \mathrm{~h}$ long, which is significantly longer than standard sorption measurements.

While the amount adsorbed at 30 bar remains nearly the same for a high number of segments, the amount adsorbed at 1 bar decreases quite fast over the number of investigated segments. This leads to a steady increase of the deliverable capacity until the maximum in Fig. 5 is reached. For ZIF8 , this point is reached at a temperature of $83 \mathrm{~K}$ and for HKUST-1, the maximum of the deliverable capacity is not reached within 20 cycles. This is in accordance with the temperatures for the maximum deliverable capacity calculated from the isotherms at different temperatures.

In another set of experiments, the segment duration was only $30 \mathrm{~min}$, which leads to a shorter experiment time and therefore a slower increase in temperature (Fig. S13). Thus, the adsorbed amount of hydrogen at 30 bar is nearly constant over the range of investigated segments and the adsorbed amount at 1 bar decreases constantly. This leads to a steady increase of the deliverable capacity from 16 to $22 \mathrm{mg} \mathrm{g}^{-1}$ while the temperature increases only from 77 to $78 \mathrm{~K}$ for ZIF-8. This effect is particularly strong close to the maximum of the deliverable capacity.

Since the temperature dependence of the deliverable capacity was calculated from three temperatures $(77,195$, and $273 \mathrm{~K}$ ) only, the maximum of the deliverable capacity is only interpolated. In order to obtain more reliable values, isotherms at different temperatures were measured exemplary for zeolite Ca-A and ZIF-8 to determine the deliverable capacity from the isotherms directly (Figs. 7, 8, and 9 ). The Tóth isotherm was used for fitting all measured isotherms at once for each material.

Figure 9 shows measured deliverable capacity between 1 and 29 bar in comparison with the calculated deliverable capacity from the Tóth fit and the calculated deliverable capacity from the measurements with the magnetic suspension balance. A pressure of 29 bar was chosen due to the restrictions of the CCSU; the deliverable capacity was calculated with the same pressure range for data from the MSB, as well. While the general shape of them is the same, deliverable capacity measured with the MSB is about $2-3 \mathrm{mg} \mathrm{g}^{-1}$ higher than measured and calculated from the CCSU. This
Fig. 6 Cycle measurements of the hydrogen capacity of ZIF-8 (left) and HKUST-1 (right) with a segment duration of $60 \mathrm{~min}$. Adsorbed amount at 30 bar: blue; adsorbed amount at 1 bar: red; deliverable capacity: green; white points: temperature
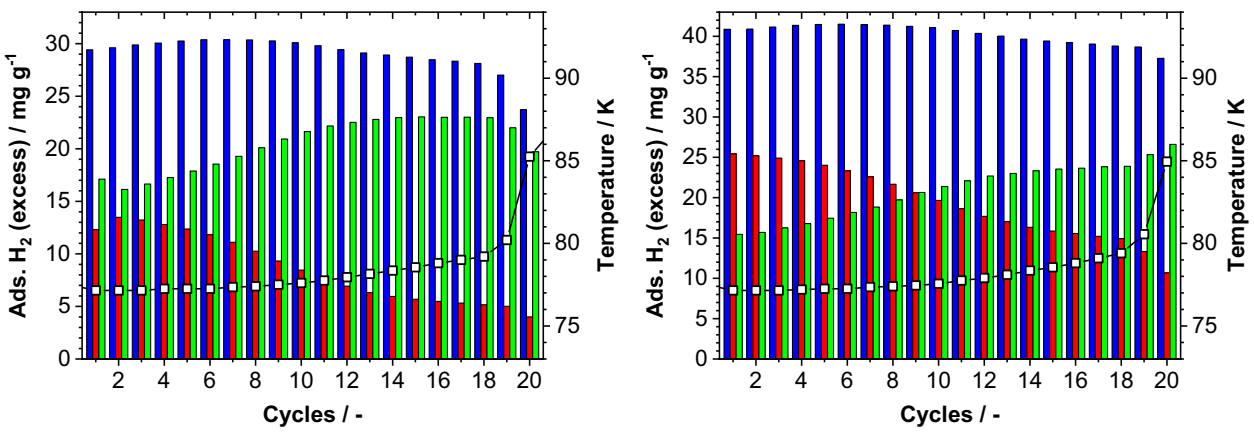


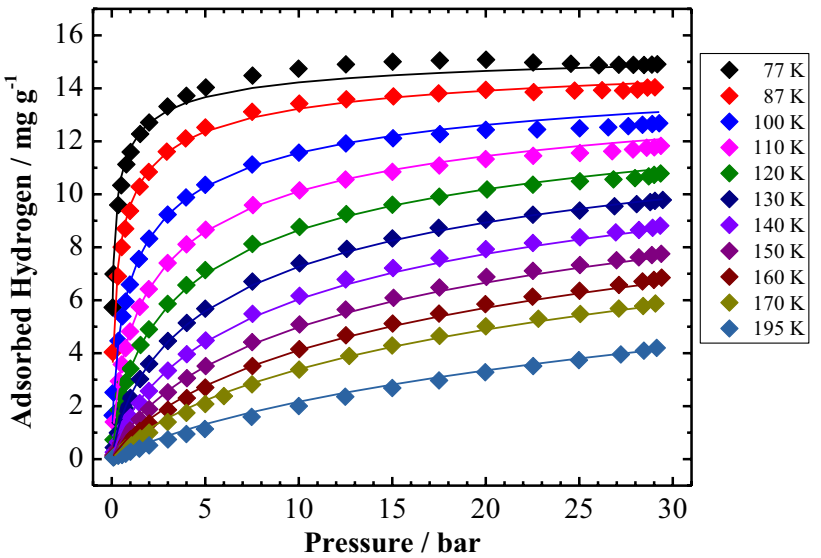

Fig. 7 Excess hydrogen sorption isotherms of zeolite Ca-A between 77 and $195 \mathrm{~K}$ with a single Tóth fit for all isotherms

overestimation can be described by the use of only three temperatures over a wide temperature range (77-273 K), while with the CCSU many temperatures in a smaller range from 70 to $195 \mathrm{~K}$ were recorded and used for the calculation.

Until now, the sorption isotherms described the excess adsorption, which is the quantity measured in an experiment. It can be considered as the excess amount of adsorptive inside the pores in comparison to non-adsorbing pore gas, which is helium in our case [14]. According to Bimbo et al., the absolute and total amount of adsorptive can be calculated with the following equation [35]. In order to calculate the absolute adsorption, the density of adsorbed hydrogen is needed. Usually, it is assumed that this density is the same as the density of liquid hydrogen at $20 \mathrm{~K}(0.0708 \mathrm{~g} \mathrm{ml})$ [16], while others report values lower [10] or higher [35] than that value. However, for our calculation, we used the density of liquid hydrogen at $20 \mathrm{~K}$. The total amount of adsorbed

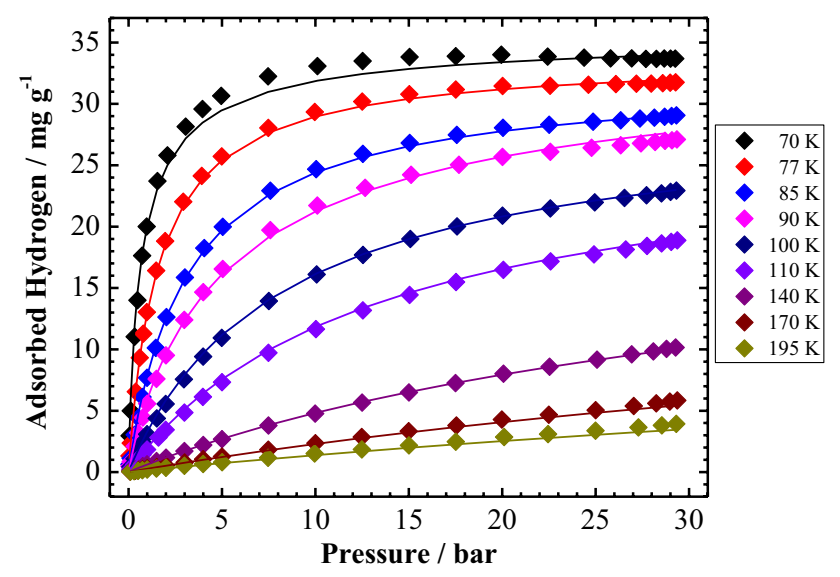

Fig. 8 Excess hydrogen sorption isotherms of ZIF- 8 between 70 and $195 \mathrm{~K}$ with a single Tóth fit for all isotherms

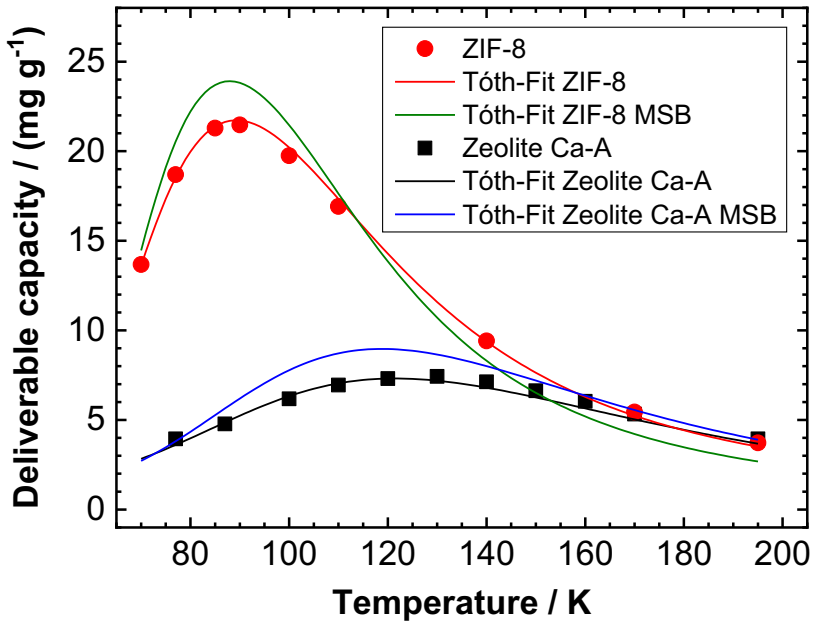

Fig. 9 Temperature-dependent deliverable capacity of ZIF-8 and Zeolite Ca-A measured with the CCSU in comparison with Tóth fits from the CCSU and MSB isotherms, respectively

hydrogen can be calculated using the bulk density of hydrogen and the pore volume of the investigated material.

$m_{\text {excess }}=m_{\text {absolute }} \cdot\left(1-\frac{\rho_{H_{2}}}{\rho_{H_{2}, a d s}}\right)$

$m_{\text {total }}=m_{\text {excess }}+\rho_{\mathrm{H}_{2}} \cdot V_{\text {Pore }}$

The Tóth fit parameters for excess, absolute, and total adsorption of ZIF-8 and zeolite Ca-A are summarized in Table 5 . The value of maximum capacity $\left(q_{\max }\right)$ rises from excess over absolute to total adsorption, while the heatrelated value $(Q)$ decreases. The maximum capacity (compare Eq. (9), shows no temperature dependency $(\chi=0)$.

With the help of the fitted Tóth parameters, the deliverable capacity between 1 and 29 bar for excess, absolute, and total adsorption for ZIF-8 and Zeolite Ca-A was calculated (Fig. 10). While the maximum deliverable capacity for both materials increases by $20 \%$, the corresponding temperature drops only by 2 to $5 \mathrm{~K}$. Thus, the determination of the deliverable capacity, its maximum, and the corresponding temperature by excess adsorption is a good measure to get an estimate without knowing the actual total adsorption.

In Fig. 11 , the usable fraction calculated from the maximum deliverable capacity at the optimum temperature and the capacity at $77 \mathrm{~K}$ and 30 bar is plotted versus the optimal operation temperature. In line with work by Schlichtenmayer and Hirscher [24] on 12 different MOFs, the usable fraction decreases with an increasing optimum operating temperature. Our experimental results are in good agreement with a recent meta-learning study by Sun et al. on a wide range of MOFs and all-silica zeolite structures confirming that the

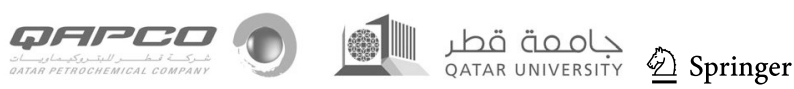


Table 5 Tóth Fit parameters for hydrogen adsorption isotherms of zeolite Ca-A and ZIF-8. The fits involve isotherms at temperatures between 70 and $195 \mathrm{~K}$ and were calculated for the excess, absolute, and total adsorption

\begin{tabular}{lrrrrrrr}
\hline & \multicolumn{2}{l}{ Zeolite Ca-A } & & & ZIF-8 & & \\
\cline { 2 - 3 } & Excess & Absolute & Total & & Excess & Absolute & Total \\
\hline $\mathrm{q}_{\max } /\left(\mathrm{mg} \mathrm{g}^{-1}\right)$ & 15.95 & 19.29 & 20.60 & & 32.80 & 41.43 & 42.97 \\
$\chi^{/-}$ & 0.00 & 0.01 & 0.00 & & 0.00 & 0.00 & 0.00 \\
$\mathrm{Q} /\left(\mathrm{kJ} \mathrm{mol}^{-1}\right)$ & 8.39 & 8.48 & 7.88 & & 5.59 & 5.30 & 4.85 \\
$\mathrm{~b}_{\infty} / 10^{-4} \mathrm{bar}^{-1}$ & 1.56 & 1.42 & 2.12 & & 1.39 & 1.70 & 3.03 \\
$\mathrm{t}_{0} /-$ & 0.44 & 0.37 & 0.37 & & 0.78 & 0.75 & 0.77 \\
$\alpha /-$ & 0.19 & 0.25 & 0.27 & & 0.00 & 0.00 & 0.00 \\
\hline
\end{tabular}

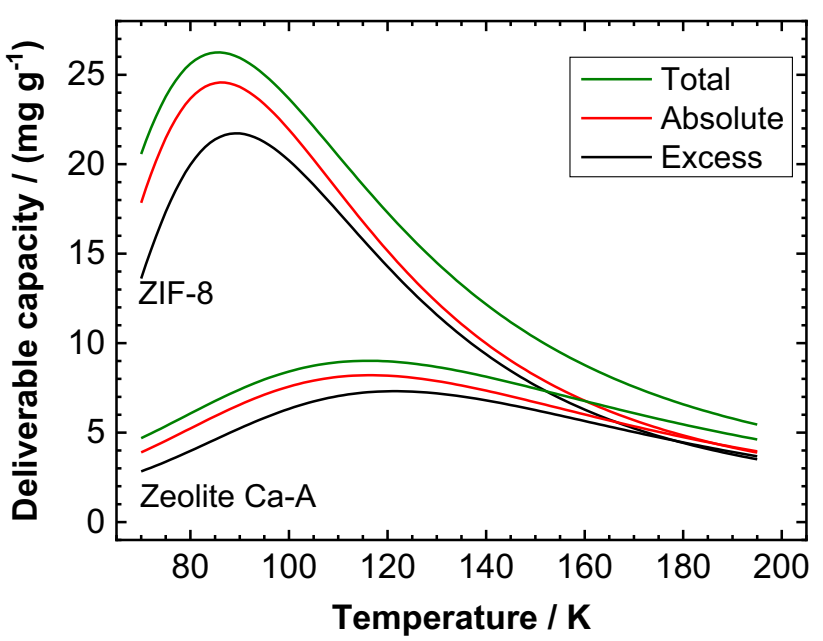

Fig. 10 Temperature-dependent deliverable capacity between 1 and 29 bar for ZIF-8 and zeolite CaA. For each material, the excess, absolute, and total adsorption capacity were calculated

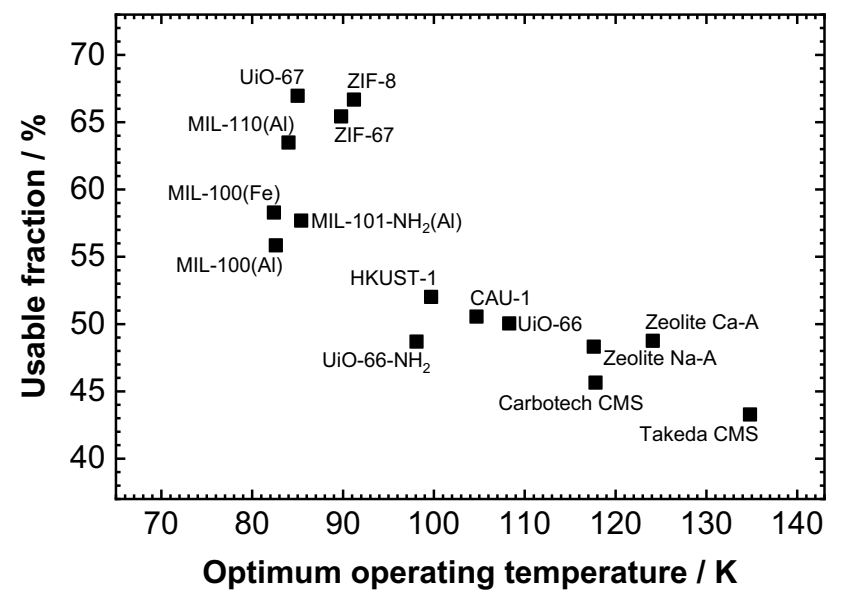

Fig. 11 Plot of the usable fraction (usable capacity at the optimum operating temperature normalized to the uptake at $77 \mathrm{~K}$ and 30 bar) of all materials versus their optimum operating temperature. There is a clear trend that materials with high optimum operating temperatures possess a low usable fraction for hydrogen storage operation optimal storage temperature for MOFs is typically below $90 \mathrm{~K}$, while most of the zeolites are above $90 \mathrm{~K}$ [36]. However, a clear correlation between pore size as well as adsorbent surface properties with respect to the optimal storage temperature and deliverable capacity has not been discovered so far. Nevertheless, the optimal storage temperature has a strong positive correlation with the isosteric heat of adsorption $[24,36]$.

\section{Conclusions}

For the evaluation of porous materials for high pressure and cryogenic temperature adsorption of hydrogen, it is not sufficient to determine the respective $\mathrm{H}_{2}$ isotherms at $77 \mathrm{~K}$. It is required to investigate the deliverable capacity in a pressure range, which has to be chosen beforehand. It seems plausible to use the pressure range between 1 and 1.5 bar and about 30 bar, which is the pressure deployable by commercial electrolyzers and steam reformers. The deliverable capacity shows a maximum at a temperature, which seems to be connected to the pore size of the adsorbent and its surface chemistry. While it is possible to determine the temperature-dependent deliverable capacity via isotherms over a range of different temperatures, a rough determination is also possible by using three temperatures, which can be easily deployed. With the use of liquid nitrogen (77 K), dry ice $(195 \mathrm{~K})$, and a standard cryostat $(273 \mathrm{~K})$, the deliverable capacity can be estimated with minimum effort. While most MOFs show optimal storage temperatures below $90 \mathrm{~K}$, many zeolites and carbons are above $90 \mathrm{~K}$ however at the expense of lower usable capacity. It is important to note that the maximum deliverable capacity is not always obtained at $77 \mathrm{~K}$, as typically assumed, but depends on the pore size and the chemical nature of the adsorbent. A smaller pore diameter results in an overlap of the van der Waals forces, thereby increasing the heat of adsorption, while, e.g., also open-metal sites show an increased heat of adsorption. Therefore, materials such as HKUST-1or MIL-100 which possess pores with different diameters as well as open-metal 
sites will have a distribution in the heat of adsorption, leading to a complex situation, since possibly a higher fraction of the uptake is non-usable at $77 \mathrm{~K}$ and below 1 bar. Future studies are directed towards this point.

Supplementary Information The online version contains supplementary material available at https://doi.org/10.1007/s42247-021-00258-7.

Funding Open Access funding enabled and organized by Projekt DEAL. This work was financially supported by Bavarian Hydrogen Center $\left(\mathrm{BH}_{2} \mathrm{C}\right)$.

\section{Declarations}

Conflict of interest The authors declare no competing interests.

Open Access This article is licensed under a Creative Commons Attribution 4.0 International License, which permits use, sharing, adaptation, distribution and reproduction in any medium or format, as long as you give appropriate credit to the original author(s) and the source, provide a link to the Creative Commons licence, and indicate if changes were made. The images or other third party material in this article are included in the article's Creative Commons licence, unless indicated otherwise in a credit line to the material. If material is not included in the article's Creative Commons licence and your intended use is not permitted by statutory regulation or exceeds the permitted use, you will need to obtain permission directly from the copyright holder. To view a copy of this licence, visit http://creativecommons.org/licenses/by/4.0/.

\section{References}

1. J.O. Abe, A.P.I. Popoola, E. Ajenifuja, O.M. Popoola, Int. J. Hydrogen Energy 44, 15072 (2019)

2. M. Fichtner, Z. Zhao-Karger, J. Hu, A. Roth, P. Weidler, Nanotechnology 20, 204029 (2009)

3. J. Gao, P. Adelhelm, M.H.W. Verkuijlen, C. Rongeat, M. Herrich, P.J.M. van Bentum, A.P.M. Gutfleisch, O. Kentgens, K.P. de Jong, P.E. de Jongh, Journal of Physical Chemistry C 114, 4675 (2010)

4. Y. Jia, C. Sun, S. Shen, J. Zou, S.S. Mao, X. Yao, Renew. Sustain. Energy Rev. 44, 289 (2015)

5. M. Taube, D. Rippin, W. Knecht, D. Hakimifard, B. Milisavljevic, N. Gruenenfelder, Int. J. Hydrogen Energy 10, 595 (1985)

6. D. Teichmann, K. Stark, K. Müller, G. Zöttl, P. Wasserscheid, W. Arlt, Energy Environ. Sci. 5, 9044 (2012)

7. G. Do, P. Preuster, R. Aslam, A. Bösmann, K. Müller, W. Arlt, P. Wasserscheid, React. Chem. Eng. 1, 313 (2016)

8. R. Chahine, T. Bose, Int. J. Hydrogen Energy 19, 161 (1994)

9. A. Züttel, P. Sudan, P. Mauron, P. Wenger, Appl. Phys. A 78, 941 (2004)

10. B. Panella, M. Hirscher, S. Roth, Carbon 43, 2209 (2005)
11. H.W. Langmi, A. Walton, M.M. Al-Mamouri, S.R. Johnson, D. Book, J.D. Speight, P.P. Edwards, I. Gameson, P.A. Anderson, I.R. Harris, J. Alloy. Compd. 356-357, 710 (2003)

12. J.G. Vitillo, G. Ricchiardi, G. Spoto, A. Zecchina, Phys. Chem. Chem. Phys. 7, 3948 (2005)

13. K. Cousins, R. Zhang, Polymers 11, 690 (2019)

14. M. Schlichtenmayer, M. Hirscher, J. Mater. Chem. 22, 10134 (2012)

15. M.P. Suh, H.J. Park, T.K. Prasad, D.-W. Lim, Chem. Rev. 112, 782 (2012)

16. K.M. Thomas, Catal. Today 120, 389 (2007)

17. B. Panella, M. Hirscher, H. Pütter, U. Müller, Adv. Func. Mater. 16, 520 (2006)

18. B. Panella, K. Hönes, U. Müller, N. Trukhan, M. Schubert, H. Pütter, M. Hirscher, Angewandte Chemie - International Edition 47, 2138 (2008)

19. ELB Elektrolysetechnik GmbH, (2017).

20. P. Häussinger, R. Lohmüller, and A. M. Watson, in Ullmann's Encyclopedia of Industrial Chemistry, 6. Edition (Wiley-VCH Verlag GmbH \& Co. KGaA, 2012), pp. 249-307.

21. S.K. Bhatia, A.L. Myers, Langmuir 22, 1688 (2006)

22. S. Tedds, A. Walton, D.P. Broom, D. Book, Faraday Discuss. 151, 75 (2011)

23. J. Purewal, D. Liu, A. Sudik, M. Veenstra, J. Yang, S. Maurer, U. Müller, D.J. Siegel, The Journal of Physical Chemistry C 116, 20199 (2012)

24. M. Schlichtenmayer, M. Hirscher, Appl. Phys. A 122, 379 (2016)

25. U. Böhme, B. Barth, C. Paula, A. Kuhnt, W. Schwieger, A. Mundstock, J. Caro, M. Hartmann, Langmuir 29, 8592 (2013)

26. S. Chavan, J.G. Vitillo, M.J. Uddin, F. Bonino, C. Lamberti, E. Groppo, K.-P. Lillerud, S. Bordiga, Chem. Mater. 22, 4602 (2010)

27. G. Majano, J. Pérez-Ramírez, Adv. Mater. 25, 1052 (2013)

28. Y.-K. Seo, J.W. Yoon, J.S. Lee, U.-H. Lee, Y.K. Hwang, C.-H. Jun, P. Horcajada, C. Serre, J.-S. Chang, Microporous and Mesoporous Maaterials 157, 137 (2012)

29. M. Thommes, K. Kaneko, A.V. Neimark, J.P. Olivier, F. Rodriguez-Reinoso, J. Rouquerol, K.S.W. Sing, Pure Appl. Chem. 87, $1(2015)$

30. J. Rouquerol, F. Rouquerol, P. Lllewellyn, G. Maurin, and K. S. W. Sing, Adsorption by Powders and Porous Solids: Principles, Methodology and Applications (Academic Press, 2014).

31. D. Duong, Do, Adsorption Analysis: Equlibria \& Kinetics (Imperial College Press, London, 1998)

32. A. Nuhnen, C. Janiak, Dalton Trans. 49, 10295 (2020)

33. V.K. Peterson, Y. Liu, C.M. Brown, C.J. Kepert, J. Am. Chem. Soc. 128, $15578(2006)$

34. Ü. Kökçam-Demir, A. Goldman, L. Esrafili, M. Gharib, A. Morsali, O. Weingart, C. Janiak, Chem. Soc. Rev. 49, 2751 (2020)

35. N. Bimbo, J.E. Sharpe, V.P. Ting, A. Noguera-Díaz, T.J. Mays, Adsorption 20, 373 (2014)

36. Y. Sun, R. F. DeJaco, Z. Li, D. Tang, S. Glante, D. S. Sholl, C. M. Colina, R. Q. Snurr, M. Thommes, M. Hartmann, and J. I. Siepmann, Science Advances, in press. 